\title{
Risk of miscarriage among users of corticosteroid hormones: a population-based nested case- control study
}

This article was published in the following Dove Press journal:

Clinical Epidemiology

7 August 2013

Number of times this article has been viewed

\author{
Anne-Mette B Bjørn' \\ Rikke B Nielsen' \\ Mette Nørgaard' \\ Ellen A Nohr ${ }^{2}$ \\ Vera Ehrenstein' \\ 'Department of Clinical Epidemiology, \\ ${ }^{2}$ Section for Epidemiology, \\ Department of Public Health, Aarhus \\ University Hospital, Aarhus, Denmark
}

Background: The purpose of this nested case-control study in Denmark was to study the association between use of corticosteroids and risk of miscarriage.

Methods: We identified prescriptions for corticosteroids before the miscarriage/index date. We estimated odds ratios (ORs) for miscarriage and for early ( $<13$ weeks) and late (13-21 weeks) miscarriage adjusting for age, history of diabetes and epilepsy, and nonsteroidal anti-inflammatory drug use.

Results: We identified 10,974 women with miscarriage and 109,740 controls. Prevalence of inhaled corticosteroid use within 60 days before the index date was $1.3 \%$ among the cases and $1.0 \%$ among the controls $(\mathrm{OR}=1.20 ; 95 \%$ confidence interval $[\mathrm{CI}] 1.01-1.44)$. Prevalence of oral corticosteroid use within 60 days before the index date was $0.3 \%$ for both cases and controls $(\mathrm{OR}=0.78 ; 95 \% \mathrm{CI} 0.53-1.15)$. For inhaled and oral corticosteroids, the ORs of early miscarriage were 1.22 (95\% CI 1.01-1.49) and 0.81 (95\% CI 0.55-1.20), respectively.

Conclusion: Use of inhaled corticosteroids was associated with a slightly increased risk of early miscarriage, but explanations alternative to causal ones were possible.

Keywords: case-control study, corticosteroid hormones, epidemiology, miscarriage

\section{Introduction}

Corticosteroid hormones are potent substances that influence the functioning of most cells in the body, ${ }^{1}$ and are used in women of childbearing age ${ }^{2,3}$ to treat asthma, rheumatoid arthritis, eczema, and inflammatory bowel disease. ${ }^{4,5}$ In Denmark, an estimated $1.7 \%$ of women who give birth use inhaled or oral corticosteroids during early pregnancy. ${ }^{6}$

Miscarriage is the most common adverse event of early pregnancy, occurring in approximately $20 \%$ of pregnancies. ${ }^{7}$ Previously, four studies have examined corticosteroid use in pregnancies ending in miscarriage, with numbers of pregnancies ranging from $313^{8}$ to $281,019 .{ }^{9}$ All of the studies, ${ }^{8-10}$ except one, ${ }^{11}$ reported an increased risk of miscarriage among women with corticosteroid intake in early pregnancy, with risk ratios ranging from 1.01 (95\% confidence interval [CI] $0.48-2.11)^{11}$ to $1.66(95 \%$ CI 1.12-2.48). ${ }^{10}$ Most published studies were conducted on small samples and not population-based. ${ }^{8,10,11}$ Potential confounding by age, smoking, and body mass index could be controlled in only one study. ${ }^{9}$ Also, no study accounted for gestational age at the time of miscarriage, although this information could reveal potential mechanisms behind the putative association.

We conducted a large population-based nested case-control study to examine the relationship between use of corticosteroids and risk of miscarriage. Further, we
Correspondence: Anne-Mette Bay Bjørn Department of Gynecology and Obstetrics, Regionshospitalet Horsens, 8700 Horsens, Denmark

Tel +4578425000

Email annbjoer@rm.dk 
examined whether the association differed for early and late miscarriage.

\section{Materials and methods Study population and duration}

The population of this case-control study stemmed from northern Denmark, which is a well-defined geographic and administrative region with a population of about 1.8 million people or $33 \%$ of the total Danish population. Approximately 23,500 births are registered each year in the region. ${ }^{12}$ The study period extended from January 1, 1997 to December 31, 2009. Denmark's tax-funded health care system ensures equal access to health services and partial reimbursement of most prescription drugs. ${ }^{13}$ The unique ten-digit personal identifier (CPR number) assigned to Danish residents at birth or upon immigration by the civil registration system ${ }^{14}$ encodes date of birth and gender, and is used in all public records, allowing for unambiguous record linkage across data from different registries.

\section{Cases}

Cases were women with a first-time miscarriage before the 22nd gestational week and no record of previous delivery. Cases were identified in the Danish National Registry of Patients (DNRP), which tracks admissions to all Danish somatic hospitals since 1977, including diagnoses and procedures; from 1995 onwards, information on outpatient visits has been included. ${ }^{15}$ Diagnoses are coded by doctors at discharge, using the International Classification of Diseases, Eighth Revision (ICD-8) before 1994 and Tenth Revision (ICD-10) thereafter. Gestational age at miscarriage has been reported to the DNRP since 1997 and is registered at diagnosis. Gestational age in Denmark is estimated mainly on the basis of ultrasound examination. ${ }^{16}$ The index date for the cases was the date of an inpatient or outpatient hospital visit with a diagnosis of miscarriage. We further divided miscarriage into early miscarriage as occurring in the first trimester (up to 12 completed gestational weeks) and late miscarriage as occurring in the second trimester (from gestational week 13 until gestational week 22).

\section{Controls}

Controls were women without a history of miscarriage, delivering their first live newborn. To identify controls, we used the Danish Medical Birth Registry, ${ }^{17}$ which has tracked all births in Denmark since 1973. For each case, we sampled 10 controls from women whose estimated date of conception (date of delivery minus recorded gestational length plus 14 days) was in the same calendar year as that of the case.
The index date for controls was the date on which the fetus had the same gestational age as the fetus of the calendar-year matched case woman at the date of miscarriage.

\section{Use of corticosteroids}

We used the Aarhus University Prescription Database to identify prescriptions for inhaled and oral corticosteroids filled by cases and controls before the index date. This database tracks prescriptions of reimbursed drugs sold at community pharmacies in northern Denmark. ${ }^{18}$ Inhaled and oral corticosteroids, which are available by prescription only, are eligible for general reimbursement in Denmark and thus generate records in the database. For all relevant prescriptions filled by the women in our study, we noted date of dispensation and type of drug, coded according to the Anatomical Therapeutic Chemical classification system. In some areas of the region, data on dispensations were available starting in 1998. We restricted our sample to women whose prescriptions, based on their place of residence, were expected to be recorded in the database for a minimum of one year before the index date.

Use was defined as a record of at least one relevant prescription. We defined the following categories of inhaled or oral corticosteroid users according to the recency of their last prescription relative to the index date: current users, with the most recent prescription filled within 60 days before the index date; recent users, with the most recent prescription filled 61-180 days before the index date; former users, with the most recent prescription filled more than 180 days before the index date; and never users, with no record of dispensed inhaled or oral corticosteroids in the prescription database before the index date (the reference group). Within the category of current users, we singled out new users, whose first recorded prescription of inhaled or oral corticosteroids was dispensed within 60 days before the index date.

\section{Potential confounders}

From the DNRP, we obtained information about maternal diagnoses of diseases typically treated with corticosteroids, ie, asthma, rheumatoid arthritis, and inflammatory bowel disease, recorded from 1977 until delivery. We identified history of diabetes or epilepsy before the index date using discharge diagnoses from hospital admissions or outpatient/emergency visits or by prescriptions redeemed for antidiabetic or antiepileptic drugs. Both diseases have been associated with an increased risk of miscarriage. ${ }^{19,20}$ For the same reason, we obtained data on women's prescriptions for nonsteroidal anti-inflammatory drugs (NSAIDs) redeemed 
within 12 weeks before the index date. ${ }^{21}$ All relevant diagnostic and drug codes are listed in Supplementary Table 1.

\section{Statistical analysis}

We summarized the demographic characteristics and medical history of cases and controls. We used conditional logistic regression to estimate odds ratios (ORs) with $95 \%$ confidential intervals (CIs) for the association between corticosteroid use and risk of miscarriage, separately for oral and inhaled preparations, and adjusting for age, past medical history of diabetes and epilepsy, and NSAID use. We then examined the association of corticosteroid use separately for early and late miscarriages.

Finally, we conducted a series of sensitivity analyses. We examined whether variation in the definition of corticosteroid exposure affected the results by extending the definition of current and new use from 60 days to 90 days before the index date. We then recalculated ORs after excluding cases and controls with a history of induced abortion in order to examine the impact of previous pregnancy loss. We used $\mathrm{SAS}^{\circledR}$ version 9.2 software for all analyses (SAS Institute, Cary, NC, USA). This study was approved by the Danish Data Protection Agency (2003-41-3103).

\section{Results}

\section{Characteristics of participants}

We identified 10,974 women with first-time miscarriage and 109,740 matched controls with first-time live births. Cases were more likely than controls to be 30 years or older on the index date (34.1\% versus $26.9 \%$ ). Cases and controls were similar with respect to medical history before the index date (Table 1).

\section{Corticosteroid use}

The distribution of current, recent, and former corticosteroid use was similar between cases and controls (Table 1). For inhaled corticosteroids, the adjusted OR for miscarriage was $1.20(95 \%$ CI 1.01-1.44) for current use and 1.05 (95\% CI 0.96-1.15) for former use (Table 2). For oral corticosteroid use, the adjusted OR for miscarriage was $0.78(95 \%$ CI $0.53-1.15)$ for current use and 1.07 (95\% CI 0.97-1.18) for former use.

\section{Early versus late miscarriage}

Early miscarriages accounted for 9,735/10,974 of all recorded miscarriages (88.7\%). Among women with early miscarriage, $129(1.3 \%)$ were current users of inhaled corticosteroids while $11(0.9 \%)$ women with late miscarriage were current users of these medications. Table 3 shows the ORs for early and late
Table I Characteristics of women with a first-time miscarriage (cases) and women with a first live birth (controls), northern Denmark, 1997-2009

\begin{tabular}{|c|c|c|}
\hline & $\begin{array}{l}\text { Cases } \\
\text { n (\%) }\end{array}$ & $\begin{array}{l}\text { Controls } \\
\text { n (\%) }\end{array}$ \\
\hline Total number & 10,974 & 109,740 \\
\hline \multicolumn{3}{|l|}{ Corticosteroid use } \\
\hline \multicolumn{3}{|l|}{ Corticosteroids, overall } \\
\hline Current & $165(1.5)$ & $\mathrm{I}, 447(\mathrm{I} .3)$ \\
\hline Recent & $118(1.1)$ & $\mathrm{I}, 286(\mathrm{I} .2)$ \\
\hline Former & $976(8.9)$ & $9,213(8.4)$ \\
\hline Never & $9,768(89.0)$ & $98,291(89.6)$ \\
\hline New & $19(0.2)$ & $245(0.2)$ \\
\hline \multicolumn{3}{|l|}{ Inhaled corticosteroids* } \\
\hline Current & I 40 (I.3) & $\mathrm{I}, \mathrm{I} 43(\mathrm{I} .0)$ \\
\hline Recent & $87(0.8)$ & $907(0.8)$ \\
\hline Former & $575(5.2)$ & $5,496(5.0)$ \\
\hline Never & $10,172(92.7)$ & $102,194(93.1)$ \\
\hline New & $9(0.1)$ & $95(0.1)$ \\
\hline \multicolumn{3}{|l|}{ Oral corticosteroids $a$} \\
\hline Current & $28(0.3)$ & $34 \mid(0.3)$ \\
\hline Recent & $35(0.3)$ & $4 I I(0.4)$ \\
\hline Former & $474(4.3)$ & $4,387(4.0)$ \\
\hline Never & $10,437(95.1)$ & $104,60 \mid(95.3)$ \\
\hline New & $10(0.1)$ & I7| (0.2) \\
\hline \multicolumn{3}{|l|}{ Potential confounders } \\
\hline \multicolumn{3}{|l|}{ Age at index date } \\
\hline$<25$ years & $2,931(26.7)$ & $28,523(26.0)$ \\
\hline $25-29$ years & $4,302(39.2)$ & $51,694(47.1)$ \\
\hline$\geq 30$ years & $3,74 I(34.1)$ & $29,523(26.9)$ \\
\hline \multicolumn{3}{|l|}{ Past medical history } \\
\hline Asthma & $343(3.1)$ & $2,982(2.7)$ \\
\hline Rheumatoid arthritis & $30(0.3)$ & $|7|(0.2)$ \\
\hline Inflammatory bowel disease & $76(0.7)$ & $838(0.8)$ \\
\hline Diabetes & $175(1.6)$ & I,7I5 (I.6) \\
\hline Epilepsy & $233(2.1)$ & 2,034 (I.9) \\
\hline Use of NSAIDs & $44 \mid(4.0)$ & $3,469(3.2)$ \\
\hline
\end{tabular}

Note: *Inhaled corticosteroids are mainly used to treat asthma; aoral corticosteroids are mainly used to treat inflammatory bowel disease and rheumatoid arthritis. Abbreviation: NSAIDs, nonsteroidal anti-inflammatory drugs.

miscarriage according to inhaled and oral corticosteroids. For current users of inhaled corticosteroids, the adjusted ORs for early and late miscarriage were 1.22 (95\% CI 1.01-1.49) and 1.06 (95\% CI 0.56-1.99), respectively. Only $27(0.3 \%)$ women with early miscarriage and one woman with late miscarriage were current users of oral corticosteroids.

\section{Sensitivity analyses}

When the definition of current use was extended to 90 days before the index date, prevalence of current use of inhaled corticosteroids was $1.5 \%$ among the cases and $1.3 \%$ among the controls (adjusted OR 1.09; 95\% CI 0.92-1.28). According to the extended definition, prevalence of current use of oral corticosteroids was $0.3 \%$ among the cases 
Table 2 Use of inhaled and oral corticosteroids and miscarriage among women in northern Denmark, 1997-2009

\begin{tabular}{|c|c|c|c|}
\hline $\begin{array}{l}\text { Corticosteroid } \\
\text { use }\end{array}$ & $\begin{array}{l}\text { Case/control } \\
\text { ratio }\end{array}$ & $\begin{array}{l}\text { Unadjusted } \\
\text { OR (95\% Cl) }\end{array}$ & $\begin{array}{l}\text { Adjusted } \\
\text { OR }^{*}(95 \% \mathrm{Cl})\end{array}$ \\
\hline \multicolumn{4}{|c|}{ Corticosteroids overall } \\
\hline Current & $165 / 1,447$ & $1.15(0.97-1.35)$ & I.II (0.95-I.3I) \\
\hline Recent & II8/I,286 & $0.92(0.76-I .12)$ & $0.92(0.76-I . I I)$ \\
\hline Former & $976 / 9,213$ & $1.07(1.00-1.14)$ & $1.07(0.99-1.14)$ \\
\hline Never & $9,768 / 98,291$ & Reference & Reference \\
\hline New & $19 / 245$ & $0.78(0.49-$ & $0.75(0.47-1.19)$ \\
\hline \multicolumn{4}{|c|}{ Inhaled corticosteroids } \\
\hline Current & $140 / 1,14$ & $1.23(1.03-1.47)$ & $1.20(1.01-1.44)$ \\
\hline Recent & $87 / 907$ & $0.95(0.76-1.19)$ & $0.94(0.75-1.17)$ \\
\hline Former & $575 / 5,496$ & $1.05(0.96-1.15)$ & $1.05(0.96-1.15)$ \\
\hline Never & $10,172 / 102,194$ & Reference & Reference \\
\hline New & $9 / 95$ & $0.92(0.46-1.82)$ & $0.86(0.43-1.72)$ \\
\hline \multicolumn{4}{|c|}{ Oral corticosteroids } \\
\hline Current & $28 / 341$ & $0.82(0.56-1.21)$ & $0.78(0.53-1.15)$ \\
\hline Recent & $35 / 4 I I$ & $0.85(0.60-1.21)$ & $0.85(0.60-1.20)$ \\
\hline Former & $474 / 4,387$ & $1.08(0.98-1.19)$ & $1.07(0.97-1.18)$ \\
\hline Never & $|0,437 /| 04,60 \mid$ & Reference & Reference \\
\hline New & $10 / 17 \mid$ & $0.60(0.32-1.14)$ & $0.57(0.30-1.07)$ \\
\hline
\end{tabular}

Note: *Adjusted for age at index date, history of diabetes and epilepsy, and use of NSAIDS 12 weeks before the index date.

Abbreviations: OR, odds ratio; $\mathrm{Cl}$, confidence interval; NSAIDs, nonsteroidal antiinflammatory drugs.

and $0.4 \%$ among the controls (adjusted OR 0.74; 95\% CI 0.52-1.05). Excluding 1,585 cases (14.4\%) and 13,197 controls $(12.0 \%)$ with a record of induced abortion did not change the interpretation of the overall results (data available on request).

\section{Discussion}

In this large population-based, case-control study, current use of inhaled corticosteroids was associated with a slightly increased risk of miscarriage during the first 12 weeks of gestation as compared with no recorded use. There was no evidence of an association between use of oral corticosteroids and risk of miscarriage.

Our study extends earlier research by including information on gestational age at miscarriage. Because the etiology of miscarriage varies according to gestational age, ${ }^{22}$ an association between corticosteroid exposure and early but not late miscarriage is an important finding. An early miscarriage may represent fetal loss secondary to malformation incompatible with fetal survival. Studies of maternal use of inhaled and oral corticosteroids in early gestation and risk of congenital malformations in offspring have been inconclusive. ${ }^{4,6,10,11,23-30}$ Selection bias arising from early-gestation miscarriage of malformed embryos could explain the lack of an apparent association, if such an association exists. ${ }^{31,32}$

Presence of an association with miscarriage for inhaled but not oral corticosteroids is counterintuitive. Oral corticosteroids reach higher concentrations in the maternal circulation $^{1}$ and therefore could be expected to lead to higher levels of fetal exposure. An abnormal maternal immune response has been assumed to act as an initiator of miscarriage. ${ }^{22,33}$ The anti-inflammatory effect of corticosteroids might protect against this if given in high doses. In fact, high doses of corticosteroids are used to prevent recurrent miscarriages, ${ }^{34}$ although the effectiveness of this treatment is still controversial. ${ }^{34-36}$

The association observed for inhaled corticosteroids may be due to confounding by asthma, ${ }^{37}$ because asthma is a common indication for inhaled corticosteroids. Asthma exacerbations induce hypoxia and may induce

Table 3 Use of oral and inhaled corticosteroid prescriptions stratified by early miscarriage (gestational weeks I-12) or late miscarriage (gestational weeks I3-2I), northern Denmark, 1997-2009

\begin{tabular}{|c|c|c|c|c|c|c|}
\hline \multirow{2}{*}{$\begin{array}{l}\text { Corticosteroid } \\
\text { use }\end{array}$} & \multicolumn{3}{|c|}{ Early miscarriage } & \multicolumn{3}{|c|}{ Late miscarriage } \\
\hline & $\begin{array}{l}\text { Case/control } \\
\text { ratio }\end{array}$ & $\begin{array}{l}\text { Unadjusted OR } \\
(95 \% \mathrm{Cl})\end{array}$ & $\begin{array}{l}\text { Adjusted OR* } \\
(95 \% \mathrm{CI})\end{array}$ & $\begin{array}{l}\text { Case/control } \\
\text { ratio }\end{array}$ & $\begin{array}{l}\text { Unadjusted OR } \\
(95 \% \mathrm{CI})\end{array}$ & $\begin{array}{l}\text { Adjusted OR* } \\
(95 \% \mathrm{Cl})\end{array}$ \\
\hline \multicolumn{7}{|c|}{ Inhaled corticosteroids } \\
\hline Current & $129 / 1,047$ & I.24 (I.03-I.49) & $1.22(1.01-1.49)$ & $11 / 96$ & $1.09(0.58-2.04)$ & $1.06(0.56-1.99)$ \\
\hline Recent & $74 / 786$ & $0.93(0.73-1.18)$ & $0.92(0.72-I .17)$ & $|3 /| 2 \mid$ & 1.07 (0.60-I.9I) & I.06 (0.59-I.89) \\
\hline Former & $515 / 4,867$ & $1.06(0.97-1.17)$ & 1.07 (0.97-I.I7) & $60 / 629$ & $0.95(0.72-1.25)$ & $0.97(0.74-1.27)$ \\
\hline Never & $9,017 / 90,650$ & Reference & Reference & $\mathrm{I}, 155 / \mathrm{II}, 544$ & Reference & Reference \\
\hline New & $9 / 88$ & $0.99(0.50-1.97)$ & $0.93(0.47-1.86)$ & $0 / 7$ & - & - \\
\hline \multicolumn{7}{|c|}{ Oral corticosteroids } \\
\hline Current & $27 / 318$ & $0.86(0.58-1.27)$ & $0.8 \mathrm{I}(0.55-\mathrm{I} .20)$ & $\mathrm{I} / 23$ & $0.4 I(0.06-3.06)$ & - \\
\hline Recent & $32 / 367$ & $0.87(0.61-1.25)$ & $0.87(0.60-1.25)$ & $3 / 44$ & $0.70(0.22-2.26)$ & $0.68(0.21-2.20)$ \\
\hline Former & $431 / 3,884$ & I.II (I.0I-I.23) & $1.10(0.99-1.22)$ & $43 / 503$ & $0.85(0.62-1.17)$ & $0.83(0.61-1.14)$ \\
\hline Never & $9,245 / 92,781$ & Reference & Reference & I,I92/II,820 & Reference & Reference \\
\hline New & $10 / 164$ & $0.63(0.33-1.19)$ & $0.59(0.3 \mathrm{I}-\mathrm{I} .12)$ & $0 / 7$ & - & - \\
\hline
\end{tabular}

Note: *Adjusted for age at index date, history of diabetes and epilepsy, and use of NSAIDS in the 12 weeks before the index date.

Abbreviations: OR, odds ratio; $\mathrm{Cl}$, confidence interval; NSAIDs, nonsteroidal anti-inflammatory drugs. 
abnormal smooth muscle activity in the uterus, similar to airway smooth muscle contractions, and therefore could be a risk factor for miscarriage..$^{30,38,39}$ Although prevalence of asthma diagnoses between cases and controls did not differ substantially in our study, there could be residual confounding by asthma not leading to hospital contact ${ }^{37}$ and therefore not measured in our study.

Our study corroborates a large prevalence study based on The Health Improvement Network in the United Kingdom of almost 300,000 pregnancies. It was conducted to quantify risks of major adverse pregnancy outcomes and obstetric complications in women with and without asthma. The study reported a higher risk of miscarriage (adjusted OR 1.24; 95\% CI 1.17-1.34) among women who used inhaled corticosteroids compared with women who did not, after controlling for age, smoking, and body mass index. ${ }^{9}$ Similarly, a cohort study based on data from an international asthma trial reported an unadjusted relative risk for miscarriage of 1.25 (95\% CI 0.63-2.47), comparing users $(n=196)$ and nonusers $(n=117)$ of inhaled corticosteroids. ${ }^{8}$ A Canadian study based on the Motherisk Program, in which pregnant women voluntarily report information relevant to fetal safety after drug use in pregnancy, found no increased risk of miscarriage (unadjusted relative risk 1.01; 95\% CI 0.48-2.11) among users of oral corticosteroids $(n=187)$ during pregnancy compared with nonusers $(\mathrm{n}=188),{ }^{11}$ which is in line with our findings. In contrast, an Israeli study reported an unadjusted relative risk of 1.66 (95\% CI 1.12-2.48) for miscarriage among oral corticosteroid users $(\mathrm{n}=311)$ compared with nonusers $(\mathrm{n}=790) \cdot{ }^{10}$ However, because this study was based on data reported to a teratogen information service, the results could be susceptible to overestimation due to self-referral bias. ${ }^{40}$ In summary, all the evidence taken together indicates that an association with miscarriage, if it exists, seems to be restricted to inhaled corticosteroids.

Our study was population-based, and we identified cases and controls from a larger background population than earlier studies. ${ }^{8,10,11}$ We had access to complete independent registration of births, miscarriages, and prescriptions, which reduced the risk of selection and information biases. Availability of information on gestational age at miscarriage allowed us to select controls at the gestational period during which they were eligible to become cases and to ascertain corticosteroid use in the same preceding gestational period for both cases and controls. Finally, animal studies have suggested that corticosteroids reduce fetal growth. ${ }^{41}$ Therefore, corticosteroids could theoretically affect the gestational age determined by ultrasound, creating an appearance that corticosteroid-affected miscarriages occur earlier in gestation than they actually do.

We identified occurrence of miscarriage from hospitalbased diagnoses. The estimated positive predictive value of miscarriage diagnoses recorded in the DNRP is $97 \% .{ }^{42}$ Still, data may be incomplete because some women with very early miscarriage do not seek medical contact or hospitalization and are thus not registered. ${ }^{32}$ An estimated 25\% of spontaneous abortions reported by women are not registered in the DNRP. ${ }^{43}$

Information on use of corticosteroids was based on prescriptions redeemed before the occurrence of miscarriage. However, redeemed prescriptions do not fully reflect the timing of drug intake and do not include corticosteroid use during hospitalizations. Such errors are unlikely to differ by miscarriage status; as a result, estimates of association may be diluted. ${ }^{44}$

We were able to take age, history of diabetes and epilepsy, use of NSAIDs, and underlying disease into account in our analysis. Although none of these factors affected our estimates noticeably, unmeasured confounding cannot be ruled out in observational studies. Generally, the data sources used for this study, as is common for routine administrative registries, do not contain information on smoking, alcohol, body mass index, or caffeine intake. Smoking is associated with an increased risk of miscarriage. ${ }^{45,46}$ A Danish prevalence study of 832,636 live births from 1996 to 2008, with data on maternal smoking recorded in the Medical Birth Registry, reported that $18.2 \%$ of women who used corticosteroids in the first trimester smoked compared with $19.5 \%$ of nonusers. ${ }^{26}$ Thus, a positive association between corticosteroids and miscarriage is unlikely to be explained by smoking. Although our study population was larger than that in most other studies, the number of informative observations in our dataset was low in some subgroups. Therefore, some of our estimates are imprecise.

Although physicians always need to be cautious when giving medical treatment to pregnant women, not treating pregnant women could also put both mother and fetus at risk. ${ }^{47}$ For example, untreated asthma has been associated with an increased risk of maternal morbidity, eg, exacerbations. ${ }^{48}$ The evidence from our study is not sufficient to warrant discontinuation of treatment with inhaled corticosteroids during pregnancy.

In conclusion, our results suggest a slightly increased risk of early miscarriage among women who were current users of inhaled corticosteroids but explanations alternative to causal ones cannot be ruled out. 


\section{Acknowledgments}

This work was supported in part by grants from the Augustinus Foundation, the Foundation of Dagmar Marshalls, the Foundation of the Faculty of Health in the Central Region of Denmark, the Foundation of Sophus Jacobsen and Astrid Jacobsen, the Department of Clinical Epidemiology Research, and Aarhus University.

\section{Disclosure}

The authors report no conflicts of interest in this work.

\section{References}

1. Chrousos G. Adrenocorticosteroids and adrenocortical antagonists. In: Katzung B, editor. Basic and Clinical Pharmacology. 10th edition. New York, NY: McGraw-Hill Companies Inc; 2007.

2. Kwon HL, Belanger K, Bracken MB. Asthma prevalence among pregnant and childbearing-aged women in the United States: estimates from National Health Surveys. Ann Epidemiol. 2003;13: 317-324.

3. Loftus EV Jr. Clinical epidemiology of inflammatory bowel disease: incidence, prevalence, and environmental influences. Gastroenterology. 2004;126:1504-1517.

4. Carmichael SL, Shaw GM, Ma C, et al. Maternal corticosteroid use and orofacial clefts. Am J Obstet Gynecol. 2007;197:585. e1-e7.

5. McGee DC. Steroid use during pregnancy. J Perinat Neonatal Nurs. 2002;16:26-39.

6. Bay Bjørn AM, Ehrenstein V, Hundborg HH, Nohr EA, Sørensen HT, Nørgaard M. Use of corticosteroids in early pregnancy is not associated with risk of oral clefts and other congenital malformations in offspring. Am J Ther. September 24, 2012. [Epub ahead of print.]

7. Savitz DA, Hertz-Picciotto I, Poole C, Olshan AF. Epidemiological measures of the course and outcome of pregnancy. Epidemiol Rev. 2002;24:91-101.

8. Silverman M, Sheffer A, Diaz PV, et al. Outcome of pregnancy in randomized controlled study of patients with asthma exposed to budesonide. Ann Allergy Asthma Immunol. 2005;95:566-570.

9. Tata LJ, Lewis SA, McKeever TM, et al. A comprehensive analysis of adverse obstetric and pediatric complications in women with asthma. Am J Respir Care Med. 2007;175:991-997.

10. Gur C, Diav-Citrin O, Shechtman S, Arnon J, Ornoy A. Pregnancy outcome after first trimester exposure to corticosteroids: a prospective controlled study. Reprod Toxicol. 2004;18:93-101.

11. Park-Wyllie L, Mazzotta P, Pastuszak A, et al. Birth defects after maternal exposure to corticosteroids: prospective cohort study and meta-analysis of epidemiological studies. Teratology. 2000;62: 385-392.

12. The National Board of Health. Online data. Available from: http://www. sst.dk/Udgivelser/2012/Foedselsstatistikken\%202011.aspx. Accessed June 6, 2013. Danish.

13. Ministry of Health and Prevention. Report: Health Care in Denmark, 2008. Available from: http://www.sum.dk/Aktuelt/Publikationer/ Publikationer/UK_Healthcare_in_DK.aspx. Accessed June 6, 2013. Danish.

14. Pedersen C, Gotzsche H, Moller J, Mortensen PB. The Danish Civil Registration System. A cohort of eight million persons. Dan Med Bull. 2006;53:441-449.

15. Andersen TF, Madsen M, Jørgensen J, Mellemkjær L, Olsen JH. The Danish National Hospital Register: a valuable source of data for modern health sciences. Dan Med Bull. 1999;46:263-268.

16. Jørgensen FS. Organization of obstetric ultrasound in Denmark 2000 - with description of the development since 1990. Dan Med Bull. 2003;165:4404-4409.
17. Kristensen J, Langhoff-Ross, Theil Skovgaard L, Børlum Kristensen F. Validation of the Danish birth registration. J Clin Epidemiol. 1996;49: 893-897.

18. Ehrenstein V, Antonsen S, Pedersen L. Existing data sources for clinical epidemiology: Aarhus University Prescription Database. Clin Epidemiol. 2010;2:273-279.

19. Cundy T, Gamble G, Neale L, et al. Differing causes of pregnancy loss in type 1 and type 2 diabetes. Diabetes Care. 2007;30:2603-2607.

20. Pittschieler S, Brezinka C, Jahn B, et al. Spontaneous abortion and the prophylactic effect of folic acid supplementation in epileptic women undergoing antiepileptic therapy. J Neurol. 2008;255: 1926-1931.

21. Nielsen GL, Sørensen HT, Larsen H, Pedersen L. Risk of adverse birth outcome and miscarriage in pregnant users of non-steroidal anti-inflammatory drugs: population based observational study and case-control study. BMJ. 2001;322:266-270.

22. Brown S. Miscarriage and its associations. Semin Reprod Med. 2008;26: 391-400.

23. Alexander S, Dodds L, Armson BA. Perinatal outcomes in women with asthma during pregnancy. Obstet Gynecol. 1998;92:435-440.

24. Carmichael SL, Shaw GM. Maternal corticosteroid use and risk of selected congenital anomalies. Am J Med Genet. 1999;86:242-244.

25. Czeizel AE, Rockenbauer M. Population-based case-control study of teratogenic potential of corticosteroids. Teratology. 1997;56: 335-340.

26. Hviid A, Mølgaard-Nielsen D. Corticosteroid use during pregnancy and risk of orofacial clefts. CMAJ. 2011;183:796-804.

27. Källén B, Olausson PO. Use of anti-asthmatic drugs during pregnancy. 3 . Congenital malformations in the infants. Eur J Clin Pharmacol. 2007;63: 383-388.

28. Pradat P, Robert-Gnansia E, Di Tanna GC, et al. First trimester exposure to corticosteroids and oral clefts. Birth Defects Res A Clin Mol Teratol. 2003;67:968-970.

29. Rodríguez-Pinilla E, Martínez-Frías M. Corticosteroids during pregnancy and oral clefts: a case-control study. Teratology. 1998;58:2-5.

30. Schatz M, Zeiger RS, Harden K, Hoffman CC, Chilingar L, Petitti D. The safety of asthma and allergy medications during pregnancy. J Allergy Clin Immunol. 1997;100:301-306.

31. Rothman K. Measuring disease occurrence and causal effect. In: Rothman K, editor. Epidemiology - An Introduction. New York, NY: Oxford University Press Inc; 2002.

32. Weinberg CR, Wilcox AJ. Methodologic issues in reproductive epidemiology. In: Rothman K, Greenland S, Lash T, editors. Modern Epidemiology. Philadelphia, PA: Lippincott Williams and Wilkins; 2008.

33. Mellor A, Munn D. Immunology at the maternal-fetal interface: lessons for T cell tolerance and suppression. Annu Rev Immunol. 2000;18: 367-391.

34. Laskin CA, Bombardier C, Hannah ME, et al. Prednisone and aspirin in women with autoantibodies and unexplained recurrent fetal loss. N Engl J Med. 1997;337:148-154.

35. Porter TF, LaCoursiere Y, Scott JR. Immunotherapy for recurrent miscarriages. Cochrane Database Syst Review. 2006;2:CD000122.

36. Salmon JE. A noninflammatory pathway for pregnancy loss: innate immune activation? J Clin Invest. 2004;114:15-17.

37. Csizmadi I, Collet JP, Boivin JF. Bias and confounding in pharmacoepidemiology. In: a. trom B, editor. Pharmacoepidemiology. 5th ed. West Sussex, UK: John Wiley and Sons Ltd; 2005.

38. Dombrowski MP. Asthma and pregnancy. Obstet Gynecol. 2006;108: 667-681.

39. Schatz M. Asthma and pregnancy. Lancet. 1999;353:1202-1204.

40. Ehrenstein V, Sørensen HT, Bakketeig LS, Pedersen L. Medical databases in studies of drug teratogenicity: methodological issues. Clin Epidemiol. 2010;2:37-43.

41. Michael AE, Papageorghiou AT. Potential significance of physiological and pharmacological glucocorticoids in early pregnancy. Hum Reprod Update. 2008;14:497-517. 
42. Lohse SR, Farkas DK, Lohse N, et al. Validation of spontaneous abortion diagnoses in the Danish National Registry of Patients. Clin Epidemiol. 2010;2:247-250.

43. Buss L, Tolstrup J, Munk C, et al. Spontaneous abortion: a prospective cohort study of younger women from the general population in Denmark. Validation, occurrence and risk determinants. Acta Obstet Gynecol Scand. 2006;85:467-475.

44. Rothman KJ. Bias in study design. In: Rothman KJ, editor. Epidemiology - An Introduction. New York, NY: Oxford University Press; 2002.
45. Cupul-Uicab LA, Baird DD, Skjaerven R, Saha-Chaudhuri P, Haug K, Longnecker MP. In utero exposure to maternal smoking and women's risk of fetal loss in the Norwegian Mother and Child Cohort (MoBa). Hum Reprod. 2011;26:458-465.

46. Ness RB, Grisso JA, Hirschinger N, et al. Cocaine and tobacco use and the risk of spontaneous abortion. N Engl J Med. 1999;340:333-339.

47. Koren G, Pastuszak A, Ito S. Drugs in pregnancy. $N$ Engl J Med. 1998;340:333-339.

48. Rey E, Boulet LP. Pregnancy plus: asthma in pregnancy. $B M J$. 2007;334:582-585. 


\section{Supplementary Material}

Supplementary Table I Codes from the International Classification of Diseases (ICD) and Anatomical Therapeutic Chemical (ATC) classification used to identify diagnoses from the Danish National Registry of Patients and to identify dispensing of prescribed drugs from the Aarhus University Prescription Database

\begin{tabular}{|c|c|c|c|}
\hline & ICD-8 codes & ICD- 10 codes & ATC codes \\
\hline Miscarriage & 643 & O02-O03 & \\
\hline Induced abortion & $640,64 I, 642$ & O04 & \\
\hline Asthma & 493 & J45-J46 & \\
\hline Rheumatoid arthritis & $712.19,712.39,712.59$ & M05-M06 & \\
\hline Inflammatory bowel disease & $563.00,563.01,563.10,569.02$ & $\mathrm{~K} 5 \mathrm{I}-\mathrm{K} 50$ & \\
\hline Diabetes & 250 & EI0-EI4 & \\
\hline Epilepsy & 345 & G40 & \\
\hline Inhaled corticosteroids & & & $\begin{array}{l}\text { R03BA0I, R03BA02, R03BA05, R03BA07, } \\
\text { R03AK06, R03AK07 }\end{array}$ \\
\hline Oral corticosteroids & & & H02AB04, H02AB06, Н02AB07, Н02AB09 \\
\hline Nonsteroidal anti-inflammatory drugs & & & MOIA \\
\hline Antidiabetics & & & AlO \\
\hline Antiepileptics & & & N03A \\
\hline
\end{tabular}

\section{Publish your work in this journal}

Clinical Epidemiology is an international, peer-reviewed, open access journal focusing on disease and drug epidemiology, identification of risk factors and screening procedures to develop optimal preventative initiatives and programs. Specific topics include: diagnosis, prognosis, treatment, screening, prevention, risk factor modification, systematic

Submit your manuscript here: http://www.dovepress.com/clinical-epidemiology-journal reviews, risk \& safety of medical interventions, epidemiology \& biostatical methods, evaluation of guidelines, translational medicine, health policies \& economic evaluations. The manuscript management system is completely online and includes a very quick and fair peer-review system, which is all easy to use. 